\title{
LXI. Notice upon the formation of the acetous acid in the stomachs of persons who have a bad digestion communicated by M. Parmentier
}

\section{Perperes}

To cite this article: M. Perperes (1807) LXI. Notice upon the formation of the acetous acid in the stomachs of persons who have a bad digestion communicated by M. Parmentier , Philosophical Magazine Series 1, 27:108, 352-356, DOI: 10.1080/14786440708563614

To link to this article: http://dx.doi.org/10.1080/14786440708563614

曲 Published online: 18 May 2009.

Submit your article to this journal $\pi$

Џll Article views: 2

Q View related articles $₫$ 
352 Formation of the Acetous Acid in the Stomach. preceding analysis; they differ still more from those obtained by M. Lampadius. M. Klaproth finds

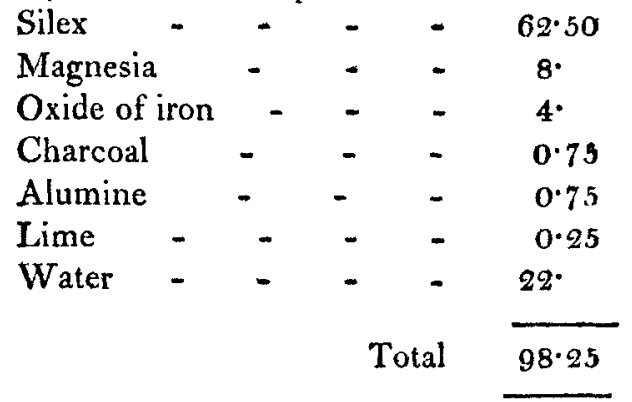

When distilled in the pneumato-chemical apparatus, a liquid is obtained of a bituminous smell, and containing a trace of ammonia. There came over also eight cubical inches of gas, which consisted of carbonic acid and of carbonated hydrogen gas, proceeding from a part of the decomposed carbon. The acids decompose this fossil without effervescence and without loss of weight, although M. Lampadius asserted that he found $0.2 \%$ of carbonic acid.

LXI. Notice upon the Formation of the Acetous Acid in the Stomachs of Persons who have a bad Digestion. By M. Perpenes, Apothecary at Azilles. Communicated by $M$. Parmentier*.

$I_{T}$ is a fact upon which all chemists are agreed, that during digestion of certain substances the acetic acid is formed: the experiments $I$ am now about to mention are therefore conformable to the phænomena that have been formerly observed. But it is not equally well admitted that the spirituous fermentation can take place in the stomach : this is only an assertion of M. Perperes himself. We are of opinion, however, that this subject is well worthy of his attention, and we invite him to pursue his researches.

For a long time every one has been convinced that fer-

* From Annales de Chimie, tom. Ix. p. 280.

mentation 
mentation is necessary to digestion, and that this fermentation may be either of a spirituous, an acid, or a putrid nature. Some alimentary substances even produce all these three effects, as has heen demonstrated by several observations. But, in general, each particular kind of food undergoes that kind of fermentation which is most analogous to its nature.

As we are acquainted with only one kind of spirituous fermentation, and only one kind of the putrid, I shall not speak of these two fermentations. But it is not the same case with the acid fermentation, because it gives rise to several acids of different natures, which it is important to know in order to fix the opinions of chemists on the subject. For this reason I determined to make the following experiments upon myself:

1st, Knowing that roasted chestnuts could not be digested by my stomach without great difficulty, and that they always created wind, followed, some moments afterwards, with an insupportable sourness on the stomach, I took eight ounces of them, which I ate without bread, after having been for thirteen hours without tasting any thing, and my stomach being perfectly empty. An hour and a half afterwards I felt a swelling in my stomach (the usual symptom with me after eating kernel substances): this announced the production of some gas, which I contrived to collect in the following manner:-I took a funnel with a long tube, which I bent into a semicircle; I placed the small end of it in the pneumatic tub, un the shelf of which there was a bell-glass filled with water; and I had the precaution to fill the tub with water, in order to cover the whole of the tube of the funnel, so that none of the gas might be lost which I might emit. Some minutes afterwards I felt the dilatation in my stomach increase, and I then belched up into the funnel the wind ont of my stomach by applying my mouth to the funnel. I emitted, at different times, a culic inch of a gas which had all the characters of the carbonic acid, which nothing belied, and a little atmospheric air, which we always swallow with our aliments, as being necessary to digestion. 


\section{Formation of the Acetous Acid in the Stomach.}

The swelling of my stomach having decreased in consequencer of the evacuation of the atmospheric air and carbonic acid, and the acid fermentation having undergone all the usual periods, according to the sourness I felt on my stomach, I proceeded to follow out my experiments.

$2 d$, It was necessary to ascertain the nature of the acid contained in my stomach; and for 'this purpose I had only one method, that of vomiting, in order to determine, by future experiments, its specific characters.

I resolved to take twenty grains of ipecacuanha diluted in three ounces of distilled water, at a single draught: a quarter of an hour afterwards I drank some warm water, to the amount of fourteen ounces, without vomiting; but three ounces more made me throw up, at two vomitings, all I had taken.

I weighed the whole I had evacuated, and had only two ounces less than what I had eaten and drunk. I do not know if the stomach had digested these two ounces of liquid, or if it had been absorbed.

A minute inspection of what $I$ had thrown up resembled feculum diluted in water; which showed that fermentation had decomposed the nutritive substance $I$ had eaten, and the more so as the smell was strongly acetous: this began to confirm the idea, which I had for a long time conceived, of the formation of vinegar in stomachs of bad digestion, and it encouraged me the more strongly to pursue my experiments.

3. I dipped in the evacuated matter turnsole paper, which was immediately reddened. I then put in some infusion of violets, which was also reddened. Being ceriain, from these trials of the re-agents, of the existence of an acid in the substance evacuated, I endeavoured to determine its nature, and had recourse to the following plan:

4. I took a glass retort, in which I put all I had vomited; I adapted a globe receiver to it, which was furnished with a tube of safety, and with a second tube which entered under a bell-glass filled with water, placed upon the shelf of the pneumatic tub, in order to receive the gases which might be dissolved in the substances which formed the sub- 
ject of my experiments. I luted the whole, and gradually increased the fire until the contents of the retort began to boil. I continued the boiling until the liquid in the retort had acquired a thick consistence. I took down the apparatus, and $I$ found in my receiver sixteen ounces and a half of a very white liquid, the smell as well as the taste of which was like that of distilled acetous acid, and possessed all the properties of the acids. As a gaseous production I had only a very little carbonic acid, which was easily recognised from the rapidity with which the bubbles of it passed through the water, as well as by their size.

5. Although the smell and taste of the produce of the distillation had already furnished me with strong proofs of the existence of the acetous acid, there certainly must have been combinations. In order to ascertain this positively, I took soda, obtained by means of alcohol, and saturated the whole liquid until it was supersaturated. I filtered and evaporated to the necessary consistence for obtaining crystals of acetate of soda: I carried into a cool place the porcelain capsule which contained the saline liquor, and next day, to my great satisfaction, observed, upon a simple inspection, that the form of the crystals (which was that of striated prisms, resembling strongly the very small crystals of sulphate of soda) was in reality that which belongs to the acetate of that name, which I tasted, and the taste of which was bitter, pungent, yielding a sharp taste at the beginning, which ended by being alkaline; and, in short, quite similar to the acetate of soda in every respect.

6. Apprehensive that the above experiments were not conclusive enough, I was anxious to satisfy myself more precisely. For this purpose I took half an ounce of the saline substance which I had obtained, and dissolved it in six ounces of distilled water. I divided this solution into two equal portions : in the one I gradually poured very pure sulphuric acid, less, however, than was necessary for the entire decomposition; and in the other I poured my solutions of barytes. The first portion, which had been decomposed by the sulphuric acid, as having more affinity for soda than this alkali has for the acetous acid, was put into a 


\section{Formation of the Acetous Acid in the Stomach.}

small retort, to which $I$ adapted a small receiver, and distilled in a moderate heat. The produce obtained in the receiver was acetous acid perfectly pure, and having a very fragrant smell; in short, it had all the properties of the above acid. In the second portion I poured a solution of barytes, until the soda was set free; I then poured into the bottle containing the acetate of barytes and the soda in solution, in order to make comparative experiments, a quantity of alcohol, which dissolves this last alkali, and allows the acetate of barytes to precipitate. I was instantly fully convinced that it was the acetous acid, and all my suspicions were realised.

It results from the experiments I have described, 1st, That the dilatation felt in the stomach in cases of bad digestion is occasioned by the formation of the carbonic acid, proceeding from a commencement of decomposition, which the nutritive substances taken as aliment undergo, particularly when they are of the natire of kernels ;

2d, That the sourness, which injures the organs of digestion, and which is sometimes felt so far up as the œesophagus, proceeds from a quantity of acetous acid, which is formed by the complete decomposition of the aliments ;

3d, That eight ounces of roasted chestnuts produced two ounces, six drachms of acetous acid, after having fermented an hour and a half in the stomach;

$4 \mathrm{th}$, and lastly, That the best method of remedying the disagrceable sensation, commonly called heart-burn, which persons of weak stomachs experience, is to take, after their meals, ten grains of columbine root with twelve grains of calcined magnesia, at one dose. This mixture constantly succeeded with me. 